\title{
MITO SIN IDEOLOGÍA: FELLMANN, VICO Y SOREL
}

\author{
Manuel Barrios Casares \\ (Universidad de Sevilla)
}

ResumEn: Se examina la trayectoria intelectual del filósofo alemán Ferdinand Fellmann, destacando el magisterio de Hans Blumenberg, pero también la notable influencia del pensamiento de Giambattista Vico en el conjunto de su obra. En particular, se analiza cómo la concepción viquiana del mito sirve de base para la crítica de Fellmann a un uso ideológico del mito.

Palabras Clave: Manuel Barrios-Casares, Ferdinand Fellmann, G. Vico, G. Sorel, H. Blumenberg, mito.

ABSTRACT: The intellectual trajectory of the German philosopher Ferdinand Fellmann is examined, highlighting the teaching of Hans Blumenberg, but also the remarkable influence of Giambattista Vico's thought in the whole of his work. In particular, it is analyzed how the viquian conception of myth serves as the basis for Fellmann's critique of an ideological use of myth.

KeYwords: Manuel Barrios-Casares, Ferdinand Fellmann, G. Vico, G. Sorel, H. Blumenberg, myth.

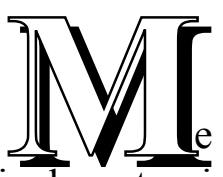

encontraba sopesando aún si mis otros compromisos de trabajo docente e investigador más inmediatos me permitirían aceptar la propuesta del director de Cuadernos sobre Vico de traducir para este número de la revista el artículo del profesor Ferdinand Fellmann «Mythos in Institutionen: Vico und Sorel», cuando me llegó la noticia del fallecimiento de este destacado catedrático emérito de filosofía de las Universidades de Münster (19801993) y Chemnitz (1993-2005) el 28 de octubre de 2019, a los setenta y nueve años de edad. Como más de una vez recordara el propio Fellmann -en parti-

Este artículo responde a una invitación expresa por parte de la Dirección de la Revista para este volumen, habiendo superado los criterios de valoración y del proceso de aceptación con informe evaluador por pares ciegos. 
cular, en el artículo mencionado- el culto a los muertos es, a juicio de Vico, una de las tres principales instituciones fundadoras de cultura. No se puede decir que la revista que lleva el nombre del filósofo napolitano haya descuidado este dictamen. Siempre se ha caracterizado por reservar un espacio de privilegio en memoria de sus grandes colaboradores desaparecidos. Era éste un motivo más, y de peso, para asumir el encargo de Cuadernos sobre Vico. A ello se añadió la ponderación más extensa que su director, el profesor José Manuel Sevilla, me hizo de este estudioso alemán del pensamiento viquiano. Esa charla me incitó a revisar la trayectoria intelectual de Fellmann. Conocía varias aportaciones suyas, derivadas de su condición de discípulo de Hans Blumenberg, algo de su aplicación de principios fenomenológicos al campo de los estudios sociales y antropológicos, así como de su propuesta última de una complementación "erótica" del logos. Pero hasta entonces no me había percatado de hasta qué punto era posible obtener una clarificadora visión de conjunto de esta obra variopinta si se la leía tomando como hilo conductor la influencia de Vico. Sin ánimo de exhaustividad, expondré a continuación unas someras consideraciones generales en ese sentido, a modo de presentación que sitúe en contexto el artículo aquí traducido y, sobre todo, como tributo de reconocimiento a la aportación filosófica de Fellmann.

Para empezar, y sin entrar en contradicción con lo que acabo de sugerir, hay que insistir en la importancia indiscutible del magisterio de Hans Blumenberg para la conformación del corpus teórico fellmanniano. ${ }^{1}$ Basta leer la semblanza biográfico-intelectual que Fellmann dedicó a su mentor ${ }^{2}$ o acercarse a su página web personal para comprobarlo. En esta última, v. g., hay toda una sección, denominada "Blumenbergiana", en la que se despliegan creativamente algunos de los más celebrados motivos del pensador de la metaforología: mito, legitimidad, distancia, inconceptuabilidad de lo real... Estos términos, así como muchas de las «metáforas de la existencia» predilectas de

1. Fellmann estudió lenguas románicas y filosofía en Gießen con Hans Robert Jauß y Hans Blumenberg. En 1965 siguió a éste en su traslado académico a Bochum, doctorándose allí en 1967. De nuevo en 1970 lo acompañó a la Universidad de Münster, donde presentó su tesis de habilitación, «Das Vico-Axiom», en 1973. Fue por tanto en relación directa con las enseñanzas del pensador de Lübeck como Fellmann fraguó su reputada interpretación de la filosofía viquiana.

2. Cfr. F. Fellmann, «Hans Blumenberg», Information Philosophie, 2008, Heft 3, pp. 49-54. 
Blumenberg (el naufragio, la salida de la caverna, la legibilidad del mundo) son recurrentes en los escritos de Fellmann, que busca darles nueva proyección especulativa, empleándolos para formular de modo más enriquecedor los interrogantes del presente. A dichos interrogantes no cabe darles respuesta definitiva, pues en este punto nuestro autor comparte las reservas kantianas de su maestro; pero justo el saber resistirse a una respuesta inmediata, establecer un trabajo de la distancia, permitir que el animal simbólico que somos medie su reacción física más primaria y elabore secundariamente representaciones de lo real que le permitan entrar en diálogo con el mundo y llegar a pactos que atenúen su absolutismo, todo eso forma parte del cometido que cabe esperar de la razón humana. Ésta, por tanto, no se constituye ni en plena autosuficiencia ni en pleno dominio de su entorno, sino sabiendo que nunca podrá tener acceso inmediato, prístino, a esa exterioridad; que necesita de un trabajo de figuración; que ella misma es, en cierta medida, resultado de ese trabajo. Esta resistencia a comprender al ser humano en términos meramente naturalistas es uno de los rasgos más acusados de la antropología fellmanniana.

Además de este primer impulso, hay en su obra una obvia presencia de la fenomenología. Fellmann asimiló los procedimientos de esta corriente filosófica de forma muy personal, profundizando en la manera en que la doctrina husserliana de la reducción se fue configurando a partir de las aportaciones de Rudolf Eucken. Su monografía La fenomenología como teoría estética le sirvió no sólo para clarificar los antecedentes del idealismo transcendental que Husserl vino a poner en circulación a partir de sus Ideen, sino también para redefinir las características y el marco de aplicación de su propio modo de entender el método fenomenológico. ${ }^{3} \mathrm{Y}$ es que Fellmann ha considerado siempre la fenomenología de un modo abierto, tratando de combinar su método con las aportaciones de una «filosofía de la vida» curada de sus primeras veleidades irracionalistas y reformulada dentro de un proyecto de ampliación de la razón. En esa línea, se ha interesado sobre todo por mostrar los fecundos vínculos que la mirada fenomenológica puede establecer con el enfoque contemporáneo más propio de los estudios culturales. Fellmann, que ya había abordado en un trabajo temprano las similitudes entre la literatura expresionista de principios del siglo XX y la cosmovisión

3. Phänomenologie als ästhetische Theorie, Alber, Friburgo/Munich, 1989. 
husserliana, ${ }^{4}$ despliega así una ambiciosa idea de la función de la estética filosófica como ámbito de comprensión de los fenómenos contemporáneos, subrayando el papel cada vez más destacado que poseen las imágenes en las formas cotidianas de comunicación humana y de representación de lo real.

En el trasfondo de todo este proyecto cabe remitirse, por supuesto, a una voluntad de reelaboración hermenéutica del bagaje fenomenológico, que es común a las trayectorias de Fellmann y Blumenberg. Ahora bien: aquí es donde tan decisiva como la de su mentor se muestra la impronta viquiana. Ella permite captar la coherencia del itinerario intelectual fellmanniano incluso ahí donde éste se aparta del magisterio del de Lübeck: una coherencia sin duda difícil de apreciar si desde un punto de vista puramente externo nos limitamos a ver en él a un investigador, en principio de corte netamente académico, que comienza estudiando diferentes momentos histórico-filosóficos del tránsito medieval y barroco a la modernidad (así en su monografía Escolástica y Reforma cosmológica $)^{5}$, pasa por una etapa intermedia de debate metodológico con diversas corrientes filosóficas del siglo veinte (fenomenología, hermenéutica, teoría crítica, pragmática) y acaba destapando su faceta más original al ponerse a oficiar de «erósofo» -según él mismo se autodenominaba en su reciente biografía intelectual ${ }^{6}$ - centrando algunos de sus últimos trabajos en la problemática de la pareja, la sexualidad, el vínculo matrimonial y otras cuestiones a medio camino entre la antropología, la reflexión moral y la divulgación filosófica. Es el análisis de las formas simbólicas en que la vida humana trata de dotarse de inteligibilidad, sin acudir al expediente de una subjetividad constituida con carácter previo y fundante o a la mera facticidad biológica, lo que distingue el empeño fellmanniano, y esto remite directamente a Vico.

Como él mismo ha explicado, el enfoque del libro que lo consagró como destacado estudioso del pensamiento viquiano, El axioma de Vico: el hombre hace la historia ${ }^{7}$ se aleja de las interpretaciones de la Ciencia nueva de corte idealista (Croce, Cassirer, etc.) y la aborda en clave pragmática: justamente en el sentido de ese axioma que considera a los hombres agentes de su propia existencia, concluyendo de ahí la actitud eminentemente pluralista que distingue la exploración de la mente humana y del espíritu de las naciones

4. Phänomenologie und Expressionismus, Alber, Friburgo/Munich, 1982.

5. Scholastik un Kosmologische Reform, Aschendorf, Münster, 1971.

6. Der Erosoph: Eine philosophische Autobiographie, Königshausen und Neumann, Friburgo/Munich, 2019.

7. Das Vico-Axiom: der Mensch macht die Geschichte, Alber, Friburgo/Munich, 1976. 
emprendida por Vico. Esta actitud supone, por una parte, una réplica decidida a la estrechez del tratamiento cartesiano de la subjetividad; y, con ello, por otra parte, una comprensión de la racionalidad de los procesos históricos que atiende antes a factores derivados de la organización del mundo social que a suplementos metafísicos. En la medida en que dichos factores no son necesariamente conscientes ni dependen directamente de la voluntad individual, Vico estaría desbordando el paradigma moderno más convencional de una teoría de la conciencia y anticipando una mirada sobre la historicidad más rica y compleja que la acuñada por las filosofías de la Historia y sus teleologías del Progreso. Con esto, de hecho, Fellmann hace de Vico un antecedente directo del proyecto metaforológico blumenbergiano, en la medida en que ya para el napolitano el impulso a la formación de metáforas se constituiría en el paradigma de la respuesta adaptativa del ser humano a esas circunstancias cambiantes, extrañas e inhóspitas que lo rodean en su estado inicial en el mundo.

De este trabajo fundacional sobre Vico, el conjunto de la obra de Fellmann extrae, en concreto, dos aspectos ligados a esta consideración. Por un lado, una manera de concebir la realidad que no se deja atrapar por las limitaciones de la noción racionalista de verdad. Y, por otro, una revalorización de la importancia de la dimensión emocional en la constitución del sujeto. Entre otros motivos porque el sujeto nunca es pensado por Vico en los términos solipsistas del cogito cartesiano. Para la experiencia de uno mismo resulta fundamental la mediación del otro. El espacio comunicativo constituye a los sujetos y de él forma parte toda una trama de elementos simbólicos, emocionales, que no se agotan en la mera presentación racionalista de la razón. Un texto de Fellmann como Filosofía de la vida: elementos de una teoría de la experiencia de sí apura estas enseñanzas viquianas y las aplica con especial tino para defender la legitimidad de una filosofía que acepte este constitutivo prerracional sin caer por ello en ninguna suerte de irracionalismo. ${ }^{8}$

En esta misma línea de ampliación del espacio de la racionalidad cabe situar sus trabajos sobre el giro icónico del mundo contemporáneo —un giro que Fellmann había descrito ya en términos de «giro imágico»» ${ }^{9}$ antes de

8. Lebensphilosophie: Elemente einer Theorie der Selbtserfahrung, Rowohlt Taschenbuch Verlag, Reinbek bei Hamburgo, 1993.

9. Traduzco «imagic turn», más que como «giro a la imagen», como «giro imágico», para recalcar el que con esta expresión quiere referirse Fellmann al hecho de que las imágenes que el hombre crea para representarse el mundo se hallan conectadas en su origen a rituales y prácticas de carácter mágico y 
que William John Thomas Mitchell acuñara su famoso «pictorial turn»—. ${ }^{\mathbf{1 0}}$ Como sugeríamos más arriba, no basta el razonamiento lógico para dar cuenta de lo real: hay dimensiones esenciales a las que sólo cabe referirse de modo indirecto, metafórico, a través de símbolos e imágenes que proyectan deseos, temores y aspiraciones que forman parte del tejido cultural y de la vida social. Vico es aquí un referente esencial para Fellmann, por cuanto su teoría del mito aporta elementos para comprender cómo se constituye el orden civil a partir del trabajo poético de un sentido común que va dando consistencia a las instituciones sobre la base de representaciones y creencias compartidas. En efecto: los universales fantásticos, forjados antes que las abstracciones lógicas, permiten a la mente humana deleitarse con lo uniforme, sin tener que extraer para ello géneros y especies supuestamente ínsitas en la naturaleza de las cosas. Aplicando estas sugerencias al presente, Fellmann propone una teoría medial de la subjetividad que hace de la interacción social el lugar de constitución tanto del yo como de los procesos históricos en que éste se ve inmerso. Valora así la rehabilitación viquiana del sentido común como una continuación de la tradición humanística que replica al modelo abstracto de una razón puramente teorética mediante la incorporación de sus factores pragmáticos y hermenéuticos: éstos la hacen arraigar siempre en un contexto histórico-social concreto, de manera que este pensamiento de la historicidad de lo humano se mantiene alejado de todo esencialismo.

Precisamente en busca de este mayor arraigo, Fellmann ha procurado perfilar mejor una concepción de la teoría que no exagere demasiado esa toma de distancia que le es característica. En Blumenberg, este rasgo se explica por su rechazo a la tendencia de los pensadores frankfurtianos a poner a la teoría al servicio de la praxis, aversión que en su caso se agudizaba cuando se trataba de Habermas. En cambio, Fellmann busca aquí puntos de encuentro. El

religioso. Rescatando el sentido de la noción de «hierofanía» habilitada por Mircea Eliade, Fellmann subraya que en toda imagen hay una dimensión en la que queda un rastro de aquella capacidad de traer a presencia algo ausente. Esto sería lo «mágico» de toda imagen. Cfr. Symbolischer Pragmatismus Hermeneutik Nach Dilthey, Rowohlt, 1991.

10. El artículo en el que W.J.T. Mitchell, formula por primera vez esta idea se publicó originalmente en 1992 en la revista ArtForum y luego fue incluido como capítulo de apertura de su libro Picture Theory (University of Chicago Press, Chicago IL, 1994). Ahí podemos leer: «Sea lo que fuere el giro pictórico, debe quedar claro que no es un retorno a la mímesis ingenua, a la copia o correspondencia de las teorías de representación, o una metafísica renovada de la "presencia" pictórica: es más bien un redescubrimiento post-lingüístico, post-semiótico de una imagen como una interacción compleja entre visualidad, aparato, instituciones, discurso, cuerpos y figuralidad». 
espacio dialógico no puede tener su base en una razón desvinculada ni en un individuo aislado. Según él, la pareja — no sólo ni necesariamente en las formas reguladas tradicionalmente por las religiones y las instituciones familiares - es un radical antropológico que nos abre a la intersubjetividad, nos libera del encapsulamiento narcisista y nos permite comprender hasta qué punto la dimensión emocional resulta fundamental para la conformación y justificación de los valores. ${ }^{11}$ Con esta «rectificación erótica», el logos se vería en realidad ampliado, más que cuestionado o suplantado. Es la manera en que Fellmann quiere replicar a una nueva forma de barbarie de la reflexión como la del mundo actual, en el que la sociedad parece desintegrarse en partículas elementales. Ante esta disolución nihilista, ni el severo cálculo de una racionalidad instrumental ni la bienintencionada apelación a una comunidad ideal de discurso parecen poseer la necesaria fuerza vinculante para atajar el mal. Su redimensionamiento erótico del logos persigue de otro modo la localización de la fuente de todo espacio dialógico. Para él, se encuentra en el amor intersubjetivo, que posibilita la forja de un mundo en común, tejiendo una red de sentido entre cosas y situaciones aparentemente inconexas entre sí, pero a las que se va dotando de la estabilidad y regularidad precisas para que acaben integrándose en el proyecto compartido por la pareja. ${ }^{12}$ En esto, su proceder no difiere demasiado del que Vico había considerado ya como propio de la creación metafórica.

De este modo, incluso en el último Fellmann, volcado a la acuñación de títulos que suenan en principio a libros de orientación filosófica con cierto componente divulgativo, sigue presente la inspiración viquiana. Tomando distancia crítica tanto del naturalismo como de la metafísica, esta filosofía suya como arte de vivir se aproxima al mundo de la pareja y explora el vínculo afectivo para mostrar otro posible modo de ingreso al mundo civil, compartido, que no se limite a los simples términos de un principio político de neutralización de la presunta conflictividad de base que el hombre arrastraría de su estado de naturaleza.

Es aquí donde se enmarca el interés de su artículo «Mythos in Institutionen: Vico und Sorel». ${ }^{13}$ Fellmann revindica en él la importancia de la «teoría sociológica del mito» esbozada por la Scienza nuova para la com-

11. Das Paar. Eine erotische Rechtfertigung des Menschen. Ed. orig.: Parerga, Berlín, 2005; reed. Alber, Friburgo, 2013.

12. Der Liebes-Code. Schlïssel zur Polarität der Geschlechter, Parerga, Berlín, 2007.

13. Originalmente publicado en: Rothfur, J., Hoffmeister, E., Koch, H.E. (eds.), Konstanten für Wirtschaft und Gesellschaft. Festschrift fir Walter Witzenmann, Konstanz, 1988, pp. 209-227. 
prensión histórica del proceso de surgimiento de los ordenamientos civiles. Hay en Vico una atención destacada a la función del mito, que permite esclarecer la dimensión simbólica siempre presente en las instituciones e indispensable para garantizar su fuerza cohesiva. Hay un reconocimiento de que la imposibilidad última de autofundación de la razón la remite al encuentro con su vertiente mitopoiética. Pero el valor de estas consideraciones no puede confundirse con una invitación a invocar el poder del mito para fundar una nueva realidad política ahí donde la crisis de legitimidad del mundo moderno ha visto erosionada la capacidad de llegar a acuerdos de sentido común. Fellmann expone en ese sentido la recepción del pensamiento viquiano en la obra del controvertido filósofo y teórico del sindicalismo revolucionario Georges Sorel (1847-1922), distinguiendo con precisión dos etapas. En la primera, Sorel se habría circunscrito a este tipo de análisis sociológico, relacionando el papel de la instancia mítica con esos órdenes morales tradicionales en los que el ritmo de los cambios sociales se modula y atenúa su intensidad. En la segunda, sin embargo, habría buscado poner el mito al servicio de la revolución, realizar con él la transformación radical, y para ello habría elaborado la idea de la huelga general revolucionaria como mito político. A esta segunda etapa pertenece un texto de Sorel tan explosivo e influyente como sus «Reflexiones sobre la violencia» (1908), que mereció un incisivo comentario, no exento de ambigüedad, por parte de Walter Benjamin. ${ }^{14}$ A la primera, en cambio, un libro menos conocido, su Estudio sobre Vico (1896). A él se remite Fellmann tanto para ponderar debidamente los logros exegéticos de Sorel como alguien que supo reconocer en Vico un pensamiento de la historicidad liberado de teleologías y determinismos, cuanto para delimitar con buen juicio la funcionalidad del mito en el horizonte de la política. Una contribución notable, sin duda, en tiempos de tentación populista de refundación radical de la política, mito del tiempo cero incluido, y que merecía rescatarse en nuestro idioma. ${ }^{15}$ Sirva, pues, de recuerdo y mínimo homenaje a la figura de este perspicaz filósofo, recientemente desaparecido.

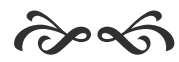

14. W. Benjamin, «Para una crítica de la violencia». Una traducción revisada del ensayo y un conjunto de contribuciones dedicadas a su análisis e interpretación puede hallarse en el volumen editado por Pablo Oyarzún, Carlos Pérez López y Federico Rodríguez, Letal e incruenta. Walter Benjamin y la crítica de la violencia. Santiago de Chile, Lom, 2017.

15. En atención al interés específico que supone la recepción de Vico por parte de Georges Sorel, ofrecemos asimismo en este número de Cuadernos sobre Vico la traducción de su escrito «Was man von Vico lernt», una especie de versión compendiada de su Étude sur Vico que Sorel publicó en el número de junio de 1898 de la revista Sozialistische Monatshefte. 